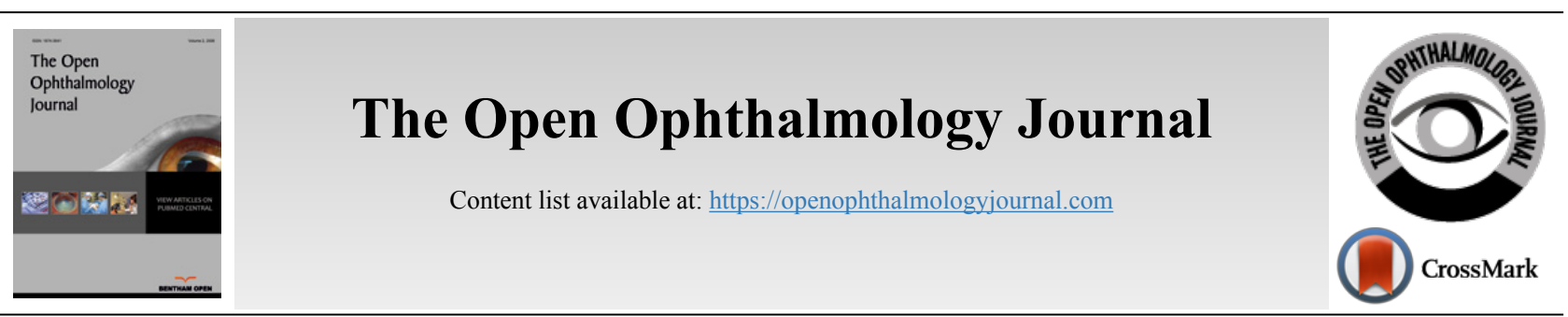

\title{
LETTER
}

\section{Retinal Self Examination "Selfies" During a Pandemic}

\author{
Ben O'Keeffe ${ }^{1}$, Sheng Chiong Hong ${ }^{2}$ and Renoh Chalakkal, ${ }^{3,4 *}$ \\ ${ }^{l}$ Wellington Eye Department, Capital Coast DHB, Wellington Hospital, Wellington, New Zealand \\ ${ }^{2}$ Department of Ophthalmology, Dunedin Hospital, Southern DHB, Dunedin, New Zealand \\ ${ }^{3}$ oDocs Eye Care, Dunedin, New Zealand \\ ${ }^{4}$ University of Auckland, Auckland, New Zealand
}

\section{Abstract:}

The advancement of smartphone camera technology allowing a smaller, high-resolution forward-facing camera on a smartphone allows a user to see the image they are about to capture of themselves at arm's length, therefore taking a 'selfie' image of themselves. The idea of a 'selfie' in a clinical setting is novel, but the exploration of this as a concept has been made necessary as COVID-19 infection and transmission risk is based on the proximity, that is, a susceptible person coming near to the person, who is infected. This report discusses an innovative smartphone-based device, oDocs nun IR, a retinal imaging device, as a tool for taking selfie retinal images/videos by patients, that could be later analyzed by the specialists/optometrists over the teleophthalmology portal.

Keywords: COVID-19, Fundus, Photo, Ophthalmology, Selfie, oDocs.

\begin{tabular}{|l|l|l|r|}
\hline Article History & Received: January 6, 2021 & Revised: June 19, 2021 & Accepted: July 29, 202
\end{tabular}

\section{INTRODUCTION}

COVID-19 has impacted the lives of every individual on a global scale. This period of global hardship will be remembered as a challenging time as nations worldwide were faced with infection and death, political crisis and gross economic instability affecting each individual's personal, physical and mental health. Historically, we have faced previous times of hardship like this and one silver lining that can be made is the advancements that it can deliver due to the collaboration between multiple nations. As a result of rapid advancements made in the scientific research, developmental and experimentation fields, scientists have already developed multiple vaccines for the COVID-19 pandemic. Furthermore, positive advances in technology due to new forced ways of thinking and paradigm shifts will create new norms as the world moves forward. During the recent COVID-19 pandemic, ophthalmic care was completely shut down, and patients with severe conditions were left unattended. Since then, many new changes have been incorporated into the eyecare domain [1,2]. One of these changes is how we manage ophthalmology consults with the creation of a device that allows self-retinal fundus examinations using a patient's own smartphone.

\footnotetext{
* Address correspondence to this author at Department of Research and Development, oDocs Eye Care, Dunedin, New Zealand;

E-mail: renohcj@odocs-tech.com
}

\section{METHODS}

Self-retinal fundus examinations use the popular technique of a person taking a 'selfie' using their smartphones. The advancement of smartphone camera technology allowing a smaller, high-resolution forward-facing camera on a smartphone, allows a user to see the image they are about to capture of themselves at arm's length, therefore, making a 'selfie' image acquisition of themselves quite easy. The application of such smartphone-based imagery to ophthalmology has been in practice for the last three to four years [3 - 5]. The idea of a 'selfie' in a clinical setting is novel, but the exploration of this as a concept has been made necessary as COVID-19 infection and transmission risk is based on the proximity factor where, a susceptible person coming near to an infected person, is considered to be of utmost risk of spreading the virus in the community.

New Zealand has been praised globally for its management of the COVD-19 virus. It has involved the use of a tiered system that aims to limit the exposure and spread of the virus while balancing the continuation of the New Zealand economy. These guidelines enforce strict rules around social distancing of at least 2 meters and reprioritising healthcare.

Ophthalmology departments in New Zealand have also had to adapt to this system whilst managing the need to treat sightsaving conditions within New Zealand. Ophthalmologists are themselves at high risk of exposure due to the virus being 
spread by aerosols, and evidence showing they can also act as fomites [6 - 8]. Community protection protocols put in place meant that waiting rooms, clinic numbers and appointments were either rescheduled or cancelled to abide by the government's rules. However, all these restrictions still mean that the ophthalmologist has to assess their patient, which is impossible due to the current technique of using a slit lamp to view the fundus. Despite protocols put in place to minimise exposure, face-to-face consultations still break current restrictions to appropriately diagnose any potential sight threatening condition [9].

This is where the introduction of the oDocs nun IR could have a large impact on the safety of diagnosing retinal conditions for the ophthalmologist and also decrease the potential risk to patients. The oDocs nun IR is a portable, infrared imaging device, which, when attached to a smartphone, can take widefield video and images of the fundus [10]. The oDocs nun IR was originally designed for use as a portable fundus camera for general practices, emergency departments and rural settings, attached to a telemedicine platform, to make eye consults more accessible and affordable. However, due to its ease of use, by combining the oDocs nun IR with the novel practice of taking a 'selfie', the patient is able to take a self-retinal image.

This technique was put to the test with a patient sitting comfortably in a dimly lit room and a sanitised oDocs nun IR device. Without the requirement to be dilated and through a pupil of at least $3 \mathrm{~mm}$, the device was placed into infrared mode and the right refractive correction for the patient was set. The patient themself then held the device parallel to their visual axis using an attached soft eye cup (for placement and correct lighting over their eye). A green flashing light within the device allowed the patient to fixate, which orientated the retina onto the screen of the smartphone for best image capture. The patient then pressed the capture button, which created a colour, 45-degree field-of-view image of the retina. The steps followed in the self-retina exam are shown in Fig. (1). Fig. (2) shows few retinal image samples taken using the nun IR device.

\section{DISCUSSION}

The importance of this novel technique would have a direct impact on both the ophthalmologist and patient, if a country is placed into a lockdown with rules similar to New Zealand's Level 3 and 4 restrictions with strict social distancing guidelines. It would directly benefit the ophthalmologist as it would mean that they would not have to break social distancing rules to view the fundus of their patient, therefore, having the ability to make an accurate diagnosis. This would also decrease the risk an ophthalmologist has to undertake, due to the exposure and transmission of the virus. It benefits the patient as they would have their retina imaged instead of being deferred and delayed. Since the device used for this selfie-retinal examination is compatible with the teleophthalmology platform developed by oDocs Eye Care [11], it helps the patient selfscreen and then consult a specialist through the virtual live consultation. It also demonstrates the added benefit of not requiring this to be in a hospital setting, therefore, decreasing the risk of exposure and transmission of the virus as they can stay in their own safe environment. Possibilities of loaning the device to patients requiring frequent monitoring by the hospitals in association with the patient's insurance provider's or through NGO's, would have to be explored further. Patients would have to be also trained appropriately by their doctor or by the technician to enable them to use the device properly. Such patient trainings could also be done virtually over the oDocs teleophthalmology platform [11]. Further, the feasibility and cost-effectiveness of such an approach needs to be studied in detail. However, this is not within the scope of this short report.

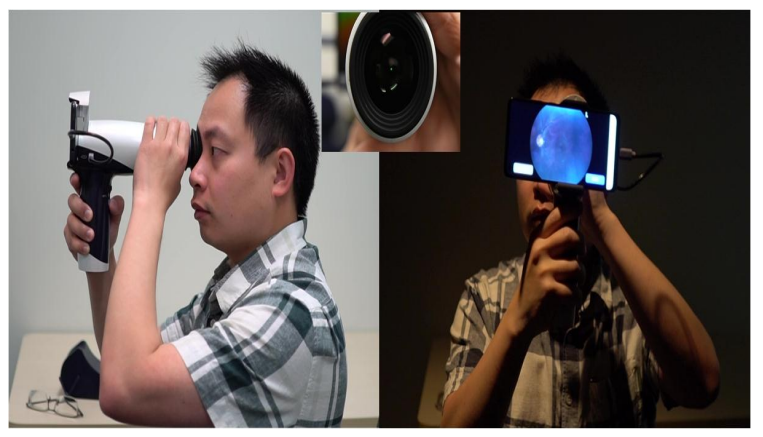

Fig. (1). Steps involved in the self-retinal examination using a nun IR device; Complete video of the process can be found using the link: Self-retinal examination.
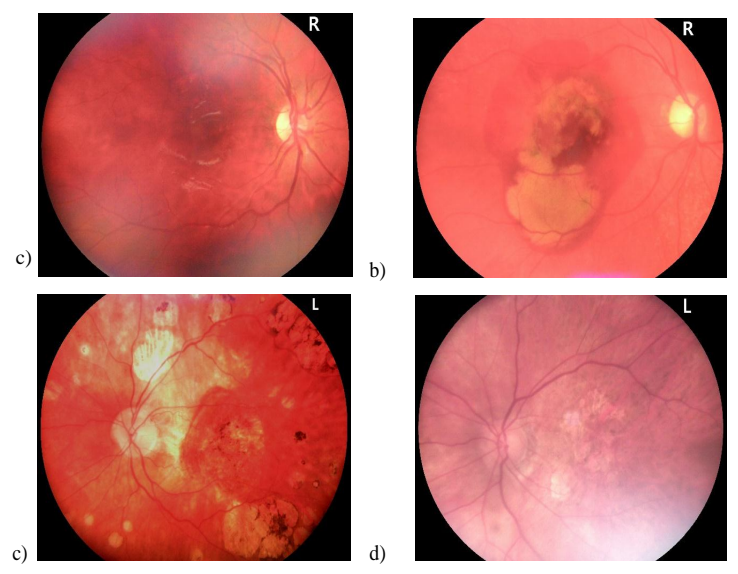

Fig. (2). Retinal images acquired using the nun IR device; a) Healthy patient, b) Macular haemorrhage secondary to age-related macular degeneration, c) myopic choroidal neovascularisation, d) geographic atrophy from age-related macular degeneration.

\section{CONCLUSION}

Further developments for the nun IR device include an artificial intelligence-based patient aide system that would enable the patients to self-screen more complex and frequent causes of vision loss, such as retinal break, peripheral retinal detachment, and macular oedema. A feature of this under development is having a voice feedback indicator when their retina is in focus. Also, an automatic referral triage system is under development which would help patients to self-refer themselves to specialists, where an AI-based classifier will triage their referrals according to different severity levels. 
Given the changes that society is being forced to adapt to in the pandemic induced lockdown conditions, we believe that the oDocs nun IR allowing self-retinal examinations could play a role in the continual diagnosis of retinal conditions as well as provide safety to ophthalmologists and patients.

\section{ETHICS APPROVAL AND CONSENT TO PARTI- CIPATE}

Not applicable.

\section{HUMAN AND ANIMAL RIGHTS}

Not applicable.

\section{CONSENT FOR PUBLICATION}

Informed consent was obtained from the participants when they were enrolled.

\section{AVAILABILITY OF DATA AND MATERIALS}

The data supporting the findings of the article will be made available by contacting oDocs Eye Care (william@odocstech.com) with reference to Retina Selfie Data.

\section{FUNDING}

None.

\section{CONFLICT OF INTEREST}

None.

\section{ACKNOWLEDGEMENTS}

Declared none.

\section{REFERENCES}

[1] Pellegrini M, Roda M, Lupardi E, Di Geronimo N, Giannaccare G, Schiavi C. The impact of COVID-19 pandemic on ophthalmological emergency department visits. Acta Ophthalmologica 2020. [http://dx.doi.org/10.1111/aos.14489]

[2] Moon J Y, Miller JB, Katz R, et al. The impact of the COVID-19 pandemic on ophthalmic care at an eye-specific emergency department in an outbreak hotspot. Clin Ophthalmol 2020 Dec 1; 14: 4155-63. PMCID: PMC7718995

[http://dx.doi.org/10.2147/OPTH.S285223] [PMID: 33293788]

[3] Shen BY, Mukai S. A portable, inexpensive, nonmydriatic fundus camera based on the raspberry pi ${ }^{\circledR}$ computer. J Ophthalmol 2017; 20174526243

[http://dx.doi.org/10.1155/2017/4526243] [PMID: 28396802]

[4] Lai K H W, Lee R P W, Yiu E P F. Ultrawide-field retinal selfie by smartphone, high-definition television, and a novel clip-on lens. Ophthalmology 2018; 125(7): 1027

[http://dx.doi.org/10.1016/j.ophtha.2018.03.027]

[5] Venkatesh P, Kumar S, Tandon N, Takkar B, Praveen PA. Selfie fundus imaging: Innovative approach to retinopathy screening. Natl Med J India 2018; 31(6): 345-6.

[http://dx.doi.org/10.4103/0970-258X.262914] [PMID: 31397367]

[6] Li R, Pei S, Chen B, et al. Substantial undocumented infection facilitates the rapid dissemination of novel coronavirus (SARS-CoV-2) Science (80-) 2020; 368(6490): 489-93

[http://dx.doi.org/10.1126/science.abb3221]

[7] van Doremalen N, Bushmaker T, Morris DH, et al. Aerosol and surface stability of SARS-CoV-2 as compared with SARS-CoV-1. N Engl J Med 2020; 382(16): 1564-7.

[http://dx.doi.org/10.1056/NEJMc2004973] [PMID: 32182409]

[8] Europe's Doctors Face Same Pitfalls as China's, Say Wuhan Medics Bloomberg. 2020 [accessed Dec. 14, 2020]; Available from: https:/www.bloomberg.com/news/articles/2020-03-17/europe-s-docto rs-getting-sick-like-in-wuhan-chinese-doctors-say

[9] COVID-19 Alert System | Unite against COVID-19. 2020 [accessed Dec. 14, 2020]; Available from: https://covid19.govt.nz/alert-system/

[10] oDocs Nun IR - Odocs Tech Com. [accessed Dec. 14, 2020]; Available from: https://odocs-tech.com/nunir

[11] oDocs Eye Care. Teleophthalmology - medicmind MedicMind 2020 [accessed Jun. 10, 2020]; Available from: https://www.medicmind. tech/teleophthalmology

(C) 2021 O’Keeffe et al.

This is an open access article distributed under the terms of the Creative Commons Attribution 4.0 International Public License (CC-BY 4.0), a copy of which is available at: https://creativecommons.org/licenses/by/4.0/legalcode. This license permits unrestricted use, distribution, and reproduction in any medium, provided the original author and source are credited. 